\title{
Configurações
}

Revista de sociologia

\section{Resistências e mudanças no "sistema político" local português: proposta de análise a partir de uma comparação internacional}

Resistance and changes in the Portuguese local "political system": proposal for a research based on international comparison

Résistance et des changements dans le «système politique» local portugais: proposition d'analyse fondée sur une comparaison internationale

\section{Joel Felizes}

\section{OpenEdition}

\section{Journals}

Edição electrónica

URL: http://journals.openedition.org/configuracoes/1846

DOI: $10.4000 /$ configuracoes. 1846

ISSN: 2182-7419

\section{Editora}

Centro de Investigação em Ciências Sociais

Edição impressa

Data de publição: 1 Junho 2013

Paginação: 175-187

ISBN: 1646-5075

ISSN: 1646-5075

\section{Refêrencia eletrónica}

Joel Felizes, "Resistências e mudanças no "sistema político" local português: proposta de análise a partir de uma comparação internacional », Configurações [Online], 11 | 2013, posto online no dia 22 setembro 2014, consultado o 01 maio 2019. URL : http://journals.openedition.org/

configuracoes/1846; DOI : 10.4000/configuracoes.1846 


\section{Resistências e mudanças no "sistema político" local português: proposta de análise a partir de uma comparação internacional}

Resistance and changes in the Portuguese local "political system": proposal for a research based on international comparison

Résistance et des changements dans le «système politique» local portugais: proposition d'analyse fondée sur une comparaison internationale

Joel Felizes

\section{0 poder local português no contexto das comparações internacionais}

Partindo da nossa experiência de pesquisa no domínio do poder local, propomo-nos ensaiar uma análise do modo como ele pode ser contextualizado face às tradições de descentralização existentes noutros países. Em jeito introdutório, com base sobretudo no trabalho de Thynne e Wettenhall (2004), fazemos uma breve análise desse problema da descentralização numa perspetiva mais ampla, apoiados no trabalho clássico de A. Macmahon (1961). Seguidamente, e acompanhando as propostas de Lidström (1999), fazemos uma retrospetiva de alguns dos trabalhos mais conhecidos que, sobretudo ao longo da década de 1990, procuraram identificar, com base em comparações internacionais, algumas das características estruturantes do poder local. Embora a intenção de vários destes trabalhos tenha sido a de encontrar uma tipologia global de poderes locais, iremos atender apenas às variáveis que estes autores julgaram mais relevantes, para desse modo produzirmos uma contextualização alargada do caso português que sirva os propósitos mais específicos de enquadramento das políticas de desenvolvimento levadas a cabo na administração local portuguesa. 


\subsection{Notas sobre a descentralização}

2 Arthur W. Macmahon, no seu livro Delegation and Autonomy, procurou explorar "a compatibilidade entre os dispositivos autónomos e os ideais integrativos da administração pública" (Macmahon, 1961: viii, apud Thynne e Wettenhall, 2004: 611). Para tal, ele foca o tema geral da descentralização, que é reconhecido como tendo muitas aplicações, sobretudo na medida em que dela resultam várias formas institucionais que têm de ser diferenciadas. O significado geral de "longe do centro" tem de ser complementado e qualificado pelo uso de outros termos com significações relacionadas. Assim, tanto uma tipologia como uma hierarquia de utilizações vão emergir.

Os componentes estruturais da descentralização são vistos por Macmahon como resultando da "interação" entre a base na qual o poder é dividido e a fonte daquele poder. A base da divisão pode ser "territorial e não territorial", sendo esta última definida como "funcional num sentido lato do termo (...) contrastando amplamente com a divisão por áreas" (Macmahon, 1961: 17, apud Thynne e Wettenhall, 2004: 611). A base territorial inclui vários tipos de governação, desde repartições locais a governos locais e mesmo estados, no caso dos sistemas federais. A base funcional compreende secções especializadas de departamentos centrais, organismos reguladores semiautónomos e forma semiautónomas (normalmente empresariais) de organização de empresas públicas.

4 Quanto à fonte do poder, Macmahon distingue três espécies da descentralização: a "devolução constitucional", a "devolução estatutária" e a "desconcentração administrativa". A descentralização é, assim, o processo geral de distribuição de poder governativo, ao passo que a desconcentração e a devolução são vistas como formas específicas da descentralização. A desconcentração é pois uma forma mais ténue de descentralização, na qual os departamentos ou outras organizações "atribuem às subunidades integradas nesses mesmos departamentos uma discricionariedade considerável", tanto em termos territoriais como funcionais, mas conservando sempre o poder para retirar aquela discricionariedade. No caso português, o exemplo mais evidente desta desconcentração é o das Comissões de Coordenação e Desenvolvimento Regional, que detêm, por exemplo, competências importantes no domínio do ordenamento do território.

5 Já a "devolução" representa um nível superior de descentralização. Quando é de tipo "estatutário", ela depende de leis emanadas de órgãos centrais legislativos que criam organizações territoriais ou funcionais e que também determinam a sua forma e a extensão dos seus poderes. No caso da "devolução constitucional", o poder é dividido "entre o governo central e unidades constitutivas de governo autónomo", não podendo este quadro ser alterado por procedimentos legislativos ordinários (Macmahon, 1961: 20-27 apud Thynne e Wettenhall, 2004: 612).

6 Esta formulação de Macmahon mostrou-se relevante por duas razões principais. Primeiro, ela reconhece a existência, na descentralização, tanto de bases territoriais como funcionais, podendo então as organizações daí resultantes ter um certo grau de autonomia legal e operacional na sua atuação. Depois, ela permite que se distingam de forma rigorosa os diferentes graus de descentralização, tanto territorial como funcional. Os termos-chave são aqui identificados e definidos, mostrando como as várias organizações podem ser estruturadas em resposta às exigências de autonomia e de integração. 
7 Daqui podemos inferir que uma parte substancial do debate em torno da descentralização pode ser enquadrada nos temas do controlo e da responsabilidade, no contexto da relação entre autonomia e integração (Thynne e Wettenhall, 2004). Esta relação, ainda que condicionada pela realização de objetivos ou por outros meios contratuais, é inevitavelmente fluida e dinâmica. A forma como aqueles controlos são feitos, bem como a definição das exigências de prestação de contas, estão associadas ao lugar que uma organização ocupa nesse eixo autonomia-integração, podendo todavia em qualquer dos polos haver efeitos positivos ou negativos. Assim, uma organização situada perto do polo da autonomia pode usufruir de elevada margem de manobra na sua gestão, num quadro de controlo menos rígido, mas, em contrapartida, ela pode estar isolada de processos deliberativos importantes na esfera governativa e ver-se privada de muitos recursos necessários. Ao invés, uma organização situada perto do polo da integração, embora funcionando dentro de um sistema rígido de controlo e de prestação de contas, tanto pode estar subjugada como pode ser capaz de interagir com outros corpos relevantes de modo bastante cooperativo.

8 As conclusões de um estudo recente de J. Rodden (2005) parecem também apontar no sentido de deverem ser tidas em conta diferenças importantes entre modelos de descentralização, até porque esta raramente significa uma redistribuição linear de poderes:

Um importante passo seria reconhecer que o melhor entendimento $d$ descentralização dos últimos 20 anos não consiste numa transferência líquida de autoridade ou de recursos fixos dos níveis centrais de governo para os subnacionais, nem entender o federalismo como a alocação fixa de esferas de autonomia do governo central e das províncias. Um ponto de partida mais promissor para a construção teórica seria a análise das causas e efeitos da distribuição imbricada e partilhada de políticas e da autoridade política e fiscal. (Rodden, 2005: 25)

Deste modo, segundo este autor, a maior parte dos argumentos teóricos que destacam os ganhos de eficiência obtidos pela descentralização (assim como os argumentos mais recentes que apontam para os perigos desta última) implicitamente assume que os avanços ou recuos na capacidade de resposta dos governos subnacionais, ou os incentivos para os esforços dos governos locais, derivam da maior autonomia em relação ao governo central. Ora, isto não é necessariamente verdade. Fazendo uma comparação com a realidade de algumas grandes empresas, Rodden explica, na mesma linha de argumentação de Thynne e Wettenhall (2004), que, se as divisões regionais duma dada empresa gastam mais do que as divisões regionais de outra, isso não reflete necessariamente uma descentralização maior da primeira, no caso de os seus gestores estarem mais sujeitos a um controlo rígido por parte da sede central e de as suas decisões sofrerem modificações frequentes. Então, no caso da descentralização das despesas públicas, as medições simplistas podem efetivamente "dizer muito pouco sobre o locus da autoridade" (Rodden, 2005: 13).

Daí que, no domínio específico da descentralização de competências e recursos em matéria de impostos, Rodden alerte especificamente para a dificuldade em "interpretar os dados sobre a descentralização das despesas sem informações adicionais sobre a estrutura que regula as finanças subnacionais" (2005: 13). 


\subsection{A comparação internacional dos governos locais}

11 Quando operamos a escalas tão alargadas como a da comparação de sistemas políticos, são normais as diferenças entre as abordagens. No caso dos poderes locais, encontramos uma variação entre estudos de cariz mais diacrónico, que atendem bastante ao enraizamento histórico dos sistemas políticos, contrapondo-se a estudos de tipo mais sincrónico, que procuram fixar no momento da sua realização um conjunto de características cuja matriz histórica é relativamente desvalorizada. Por outro lado, são também notórias as diferenças entre estudos que se centram numa única dimensão, julgada nuclear, da configuração do poder local, e estudos que apostam numa pluralidade de dimensões, para desse modo produzirem uma tipologia empiricamente mais elaborada. Como seria de esperar, qualquer destas metodologias apresenta vantagens e inconvenientes.

Bennett (1993), ao investigar o modo como as relações entre os governos central e local, em conjunto com a organização interna das autoridades locais, se modificaram ao longo do tempo, acaba por sugerir uma tipologia com três categorias de poder local: um poder local baseado no sistema napoleónico, identificável nos países de tradição latina, mas também na Alemanha, na Áustria, na Suíça e nos Países Baixos; um segundo tipo, derivado do sistema anglo-saxónico, existente na Grã-Bretanha e na Irlanda; e finalmente um terceiro tipo que advém do sistema escandinavo. Esta tipologia pecará, entre outros aspetos, por algum excesso de generalização, ao tentar abranger países geralmente julgados bastante díspares sob uma mesma tradição napoleónica.

13 Já segundo Bours (1993), no seu estudo comparativo de dezanove Estados europeus, os sistemas de governo local podem ser agrupados segundo a sua posição quanto a quatro variáveis: a dimensão demográfica; a proporção das despesas locais face ao Produto Interno Bruto do país; a proporção dessas despesas na despesa pública total; e, finalmente, a importância dos impostos locais nas receitas dos governos locais. Com base nestes critérios, o autor propõe quatro tipos de governo local:

i. o Tipo A, que compreende a Grã-Bretanha, a Irlanda, a Suécia, os Países Baixos e a Dinamarca, com governos locais mais fortes;

ii. o Tipo B, moderadamente forte, com desenvolvimentos recentes "positivos". Encontrase na Finlândia, na Alemanha Ocidental, na Bélgica e na Polónia;

iii. o Tipo C, também moderadamente forte, mas de formação mais "tradicional". Inclui o Luxemburgo, a Áustria, a Suíça, a Espanha, a Hungria e a França;

iv. o Tipo D, onde surgem a Itália, Portugal, a Grécia e a Checoslováquia, países que têm governos locais mais débeis.

Esta categorização ilustra bem algumas das dificuldades comuns a estes exercícios, já que, por exemplo, ao dar bastante importância ao fator demográfico (a dimensão populacional dos municípios), acaba por colocar a Irlanda no Tipo A, quando muitos outros autores veem este caso como o de um sistema bastante centralista de administração. Para entendermos melhor estas dificuldades de um exercício comparativo, vale a pena ainda reter mais três exemplos de investigações.

19 Norton (1994), na sua tipologia aplicada a nove países vai reter treze critérios. São convocados aspetos como o estatuto constitucional do poder local, o número de níveis de administração, os poderes formais, as formas diferentes do controlo, as modificações das funções ao longo do tempo, a situação financeira, os corpos executivos, o sistema 
eleitoral, o sistema de partidos e a participação eleitoral. O resultado é um conjunto de cinco sistemas mundiais do governo local, dos quais três são europeus: o europeu do Sul (França e Itália), o europeu do Norte (Suécia e Dinamarca) e o grupo britânico. Além destes, Norton identifica um sistema norte-americano (EUA e Canadá) e um japonês. 0 caso alemão é visto por este autor como variando entre o modelo europeu do Sul e o do Norte, dada a diversidade de situações que encontramos neste sistema federal. Goldsmith (1992), por seu turno, vai sugerir uma classificação de sistemas de poder local com base "no objetivo primordial ou ethos distintivo que estará na sua base" (Goldsmith, 1992: 395). Este autor, inspirado na metodologia de Max Weber, identifica quatro modelos diferentes, quatro tipos-ideais de poder local:

i. O modelo do Patrocinato-Clientelismo, principalmente visível na Europa do Sul da atualidade, mas também nos EUA do início do século XX. Baseia-se na lógica de líderes políticos fortes que protegem os cidadãos e são capazes de gerar benefícios para a comunidade local. Regra geral, trata-se de unidades territorialmente diminutas. Em alguns casos, como em França, esses líderes são, simultaneamente, membros de órgãos de soberania a nível regional ou central.

ii. O modelo do Desenvolvimento Económico. Encontra-se mais nos EUA da atualidade, no Canadá e na Austrália. Aqui, a tarefa básica do governo local é promover o crescimento económico no território. Emergem por isso fortes redes informais entre interesses privados e públicos, dirigidos àquele objetivo.

iii. O modelo do Estado-Providência, sobretudo visível nos governos locais da Alemanha, dos Países Baixos, da Grã-Bretanha e da Escandinávia. O governo local, normalmente grande e altamente profissionalizado, é principalmente um fornecedor de serviços de bem-estar, que devem ser oferecidos de modo eficiente e equitativo.

iv. Goldsmith sugere ainda que um quarto modelo emergiu nos últimos anos: o modelo Promotor do Mercado. Inspirado pela ideologia liberal de M. Thatcher e R. Reagan, inclui a noção de que as funções dos governos locais devem ser reduzidas a um mínimo. No caso da proposta de Lidström (1999), propõe-se uma abordagem também com base em tipos-ideais, que partem de uma separação entre sistemas políticos com presença mais ou menos forte do governo local, e entre sistemas que proporcionam maior ou menor autonomia às autarquias locais. Daqui resulta uma tipologia que permite identificar quatro categorias de sistemas em dois pares. Começando pelos casos em que os governos locais têm maior peso, fornecendo boa parte dos serviços públicos, temos:

24 i. sistema em que o poder local tem uma Posição Dominante Autónoma, que envolve maior discricionariedade dos governos locais. Não só o sector público entrega grande parte das suas tarefas ao governo local, como também este pode decidir que funções executar e como;

ii. sistema com Posição Dominante Regulada, onde ele surge mais como um agente do Estado, apesar de as suas tarefas serem relativamente extensas. 0 governo central regula e controla a forma como as entidades locais executam as suas funções.

Por contraste, em sistemas de governos locais marginais, o governo central dirige a maior parte das funções públicas. Contudo, isto não exclui a possibilidade de o governo local continuar a ter alguma importância:

i. sistema com Posição Marginal Autónoma, onde o controlo do governo central é pequeno, permitindo às entidades locais decidir de modo mais independente no quadro das suas tarefas limitadas; 
ii. sistema com Posição Marginal Regulada, onde as poucas tarefas que o governo local executa são sujeitas a regulação apertada. Esta breve resenha permite que possamos desde logo perceber que, dada a relativa generalização aqui presente, o valor destes trabalhos residirá não tanto no que é dito acerca do caso específico de cada país, mas sobretudo na forma como se procura detetar as dimensões mais relevantes para uma análise. Estas dimensões relevantes deixam, assim, entrever a possibilidade de se discutirem alguns dos pressupostos de cada sistema político, por mais enraizados que eles estejam nas tradições históricas.

\subsection{0 caso português visto numa ótica comparada}

29 Aquilo que pode ressaltar da análise cruzada de algumas destas tipificações é que o caso português não deve ser identificado como um exemplo típico de um modelo de patrocinato-clientelismo, tal como a análise de Goldsmith pode sugerir, dadas a relativa maior dimensão dos municípios portugueses e a legislação que incompatibiliza as funções autárquicas com a maior parte dos cargos nos órgãos de soberania da administração central e, enfim, dada a relativamente escassa possibilidade que as autarquias municipais têm, no quadro legal, de atrair recursos importantes para o seu território.

No caso da análise de Lidström já estamos perante o que julgamos ser uma maior aproximação ao caso português, quando se especifica o tipo de sistema em que o poder local tem uma posição globalmente marginal, mas relativamente autónoma. Importa porém ter em conta que são muitas as restrições que a legislação portuguesa impõe aos atos da administração local: daí que, em muitos domínios, as autarquias municipais portuguesas tendam a aproximar-se mais do tipo que as coloca numa posição marginal regulada. Por outro lado, não devemos esquecer o relativamente elevado estatuto político das autarquias locais portuguesas, bem como o amplo leque de competências que lhes estão atribuídas, entre outras prerrogativas que as tornam entidades dotadas de uma significativa autonomia política, administrativa e financeira.

Portanto, aquilo que parece ganhar força nestas comparações é o consenso generalizado quanto ao carácter centralista do nosso sistema político-administrativo, neste aspeto bastante longe das tradições de larga autonomia e vasto espectro de competências e recursos das administrações locais que se encontram em países como os da Europa do Norte. Assim, este carácter limitado das competências e recursos da nossa administração local, tornado visível nestas comparações internacionais, parece ser uma razão evidente das dificuldades que o poder local português tem em prosseguir os seus objetivos de promoção do desenvolvimento.

Isto mesmo é, de resto, sugerido por um reconhecido especialista na matéria, Fernando Ruivo, em declarações acerca das condições que os municípios portugueses teriam para abarcar o alargado leque de competências que o governo central propôs em 2007:

Faltam duas coisas fundamentais. Primeiro, mais recursos humanos especializados e, nesse aspecto, devo dizer que os municípios melhoraram imenso. Mas não chega, porque são áreas muito delicadas, que exigem grandes investimentos e, daí, o segundo item: recursos financeiros. Será cortando nas transferências que os municípios vão poder investir? Será que a maior parte dos 308 autarcas portugueses tem a cultura técnica necessária para levar a cabo isso, sem estarem suficientemente amparados por técnicos de alto gabarito? (Campeão das Províncias, 2007) 
É também sintoma da condição errática do nosso poder local o facto de, para muitas pessoas, o desenvolvimento local protagonizado pelas autarquias ser ainda sobretudo visto e avaliado em função da "obra feita", isto é, das suas realizações materiais (especialmente as de maior impacto visual), bem como em função de um leque de benefícios diretos proporcionados aos cidadãos (por exemplo, serviços de transportes ou fornecimento de alimentação e manuais escolares para os jovens em situação económica precária). A estes condicionalismos devem ainda acrescentar-se os que decorrem da profunda crise económica que tem afetado o país praticamente desde o início do século XXI, que se reflete inevitavelmente numa retração dos recursos financeiros do poder local. Neste quadro, um desenvolvimento regional e local sustentável afigura-se como um objetivo por cumprir, inscrito num clima de instabilidade.

\section{Os casos do défice de qualificações e da adoção da Agenda 21 Local}

34 Para ilustrar esta questão, acrescentamos seguidamente duas breves notas: a primeira, acerca das dificuldades que o poder local português tem tido em melhorar rapidamente o nível geral de qualificação dos recursos humanos sob sua jurisdição; depois, uma segunda nota sobre o grau de adoção pelas autarquias do programa de desenvolvimento sustentável da chamada Agenda 21 Local.

\subsection{Os níveis de qualificação dos recursos humanos}

35 A situação geral de carência de recursos (materiais ou humanos) é naturalmente vivida não por todos, mas seguramente pela maior parte dos municípios portugueses. Os tipos de organização interna e os níveis de qualificação dos trabalhadores das autarquias locais são bastante variáveis. Um bom exemplo desta variação pode ser percebido mediante a disparidade entre os municípios que apresentavam, em 2005, maiores e menores valores totais das despesas com pessoal. Segundo o Anuário Financeiro dos Municípios Portugueses, publicado pela Câmara dos Técnicos Oficiais de Contas (СТОС):

A despesa com pessoal é uma despesa estrutural no funcionamento da administração, directamente relacionada com as obrigações e competências do município. Assim a existência dentro do mesmo agrupamento dimensional de autarquias de uma variação significativa do peso desta despesa, entre os valores máximos e mínimos, leva-nos a sugerir a pertinência de um estudo sobre as reais necessidades de pessoal de uma autarquia e a identificar a tipologia organizacional que melhor rentabilize os recursos humanos e financeiros com vista à prossecução dos objectivos estruturais dos municípios. (Carvalho et al., 2005: 101)

Os valores aqui em causa variam de facto bastante: por exemplo, o referido Anuário mostra que esta despesa ora representa $14 \%$ do total das despesas no caso de Castelo Branco, ora chega aos $43,2 \%$ no caso de Coimbra (Carvalho et al., 2005: 101). Embora estes municípios tenham dimensão populacional diferente, trata-se, em ambos os casos, de capitais de distrito.

37 Estas variações estão igualmente relacionadas com o já referido cenário geral de baixas qualificações dos recursos humanos, particularmente gravoso se olharmos para o nosso passado recente. A percentagem de trabalhadores com qualificações de nível superior era, em 2009, de 20,6\% do total de efetivos da administração local (DGAL, 2010), ao passo que 
na administração central esse valor era de 56,2\% em setembro de 2011 (DGAEP, 2011). Situação similar pode ser verificada na proporção de trabalhadores com escolaridade básica (até nove anos): eles são 23,1\% do total de trabalhadores da administração central e representam $56,2 \%$ dos trabalhadores das autarquias locais. Ainda a propósito deste problema do défice português de qualificações, é interessante o modo como um anterior Secretário de Estado que tutelava a administração local (Eduardo Cabrita) se lhe referiu numa sessão pública:

Hoje temos, em média - e é preciso que se saiba disso - mais auto-estradas por quilómetro e por habitante que a média dos países da União Europeia. Temos já a possibilidade, em Portugal, de constituir empresas mais depressa que em qualquer país da União Europeia. Onde é que estão os nossos factores de atraso? Estão na qualificação. (Cabrita, 2008)

Não se trata contudo de um problema que derive diretamente de um hipotético estatuto político menor das autarquias locais portuguesas. De resto, se atentarmos no disposto na Carta Europeia de Autonomia Local (1985), ratificada por Portugal em 1990, percebemos que o princípio da autonomia do poder local está de facto largamente salvaguardado entre nós, no que se refere em particular à autonomia administrativa. Segundo se pode ler no Artigo 6. deste diploma, "as autarquias locais devem poder definir as estruturas administrativas internas de que entendam dotar-se, tendo em vista adaptá-las às suas necessidades específicas, a fim de permitir uma gestão eficaz". Mais adiante, é determinado que "o estatuto do pessoal autárquico deve permitir um recrutamento de qualidade baseado em princípios de mérito e de competência. Para este efeito, o estatuto deve fixar as condições adequadas de formação, de remuneração e de perspectivas de carreira" (Diário da República, 1990: 4348).

Deste modo, no nosso entender, faz sentido a ideia de que, encontrando-se o poder local português numa posição marginal do sistema político, as razões dessa marginalização não podem ser unicamente encontradas na própria legislação em vigor. Provavelmente, temos de ir buscar tais razões a um quadro de práticas políticas que desde há longos anos vem empurrando as autarquias locais (municípios e freguesias) para essa posição indesejável.

\subsection{A adoção da Agenda 21 Local}

A chamada Agenda 21 Local (A21L) é um derivado da Agenda 21, acordo que em 1992 constituiu o corolário da Cimeira da Terra promovida pela ONU (Conferência do Rio de Janeiro). No capítulo 28 da Agenda 21 visa-se, pois, um maior envolvimento entre o poder local e os agentes locais nas dinâmicas de desenvolvimento sustentável, implicando, além da administração autárquica, a participação ativa dos múltiplos sectores que constituem a sociedade civil (ONU, 1992). Quando levada a cabo, esta agenda tem, por exemplo, na figura do orçamento municipal participativo, um dos seus mais conhecidos instrumentos. No entanto, como será de prever, esta não é ainda uma prática muito comum: a RTP, num dos seus programas "iGOV" transmitido em novembro de 2012, referiu que até à data e nos últimos dez anos tinham decorrido cerca de setenta experiências de orçamentos participativos, havendo vinte que estavam em curso, envolvendo Câmaras Municipais ou Juntas de Freguesia (RTP, 2012).

41 Nas palavras de L. Schmidt e J. Guerra, "a A21L posiciona-se, assim, como um instrumento valioso não apenas no âmbito das comunidades, mas também no plano global, contribuindo para reencontrar um caminho que reintegre o local no quotidiano e, com 
base nos recursos endógenos, potencie uma prosperidade que não equivalha, necessariamente, a crescimentos inúteis e a desequilíbrios ambientais globais" (Schmidt e Guerra, 2010: 120). Segundo um estudo de 2012 coordenado pelo Grupo de Estudos Ambientais da Universidade Católica (Macedo et al., 2012), em 2011 havia 140 municípios portugueses que tinham iniciativas conhecidas no âmbito da A21L (para além de mais 27 casos a nível de freguesias). o número de municípios envolvidos, correspondendo a $45 \%$ do total de municípios portugueses, traduz um valor que podemos considerar baixo. Todavia, o estudo citado (Macedo et al., 2012) encontra outros indicadores mais preocupantes:

a) 24 municípios que subscreveram um ou os dois documentos estratégicos da A21L (a Carta de Aalborg e os Compromissos de Aalborg), até ao momento do estudo, não haviam encetado qualquer processo de Agenda 21 Local (idem: 6);

b) 23 dos 167 processos identificados deixaram de ter existência significativa (idem: 3);

c) dos 167 processos de A21L lançados, apenas uma pequena parcela (49) é visível atualmente, i.e. publicaram nos respetivos "sites" uma notícia de qualquer natureza durante o ano de 2011 (idem: 9);

d) o tipo de participação pública dominante nos processos de A21L é do tipo informativo e consultivo, sendo uma minoria os casos que recorrem a uma corresponsabilização dos cidadãos e comunidades no desenvolvimento local (idem: 11).

Deste modo, conforme alertam Schmidt e Guerra, "muitas A21L portuguesas não passam, afinal, de simulacros sem existência efectiva, e a sua permanência nas bases de dados resulta justamente da ausência de um programa ou política nacional que enquadre estas iniciativas e as avalie no terreno" (Schmidt e Guerra, 2010: 113). Mais adiante, é sublinhado que "a falta de um organismo de referência nacional que enquadre e avalie o desenrolar desse tipo de processos, permite, e porventura, estabelece, a perpetuação de situações caducas e desgastadas que vão engrossando o número de iniciativas no mapa português sem que, realmente, isso signifique muito mais do que um conglomerado impreciso de experiências fracassadas" (idem: 114).

Para além da escassez de recursos materiais e humanos qualificados, parece então confirmar-se que existe na maior parte das autarquias portuguesas um défice de capacidade de mobilização das comunidades locais e regionais, bem visível no caso da Agenda 21 Local.

\section{Conclusões}

Retomando a ideia de um poder local português marginalizado, julgamos que as razões dessa condição se prendem com vários fatores, entre os quais podemos enunciar a inexistência de dinâmicas sociais regionalistas, a prevalência de uma atuação política (central ou local) que alimenta alguma resistência à mudança, bem como uma tendência para que a adesão a iniciativas como a da Agenda 21 Local seja de tipo errático. Neste último caso, o que vemos é que se conjugam algumas situações de adoção entusiástica com muitas outras em que o entusiasmo rapidamente esmorece, ou mesmo em que não há qualquer apetência pelas eventuais vantagens de se potenciar a mobilização das comunidades locais para objetivos específicos em matéria do seu desenvolvimento. Prevalecem pois, em Portugal, os estilos de liderança "não ideológicos", usualmente pouco favoráveis à rutura e à mudança que poderiam advir dessas iniciativas. 

facto de a sua situação marginal se dever à escassez de recursos financeiros. No entanto, devemos ter em mente que em Portugal são as autarquias municipais quem executa uma parte significativa do investimento público: por exemplo, já no ano 2000 a administração local foi responsável por $37,9 \%$ das despesas de capital de todas as administrações públicas (Cunha e Silva, 2002), valor que será certamente bastante superior na atualidade. A componente do investimento tem pois uma elevada importância nos orçamentos municipais: julgamos que isto constitui, em grande medida, uma espécie de compensação pelo facto de, globalmente, os municípios terem à sua disposição orçamentos relativamente pequenos. Isto tem de resto permitido alguma margem de manobra para que as Câmaras Municipais programem e executem algumas obras vistosas: arranjos urbanísticos de grande impacte visual, complexos desportivos, habitações, recuperação de património histórico, ou outras.

Ora, o que se pode apontar à generalidade das políticas locais de desenvolvimento é o facto de, com muita frequência, terem sido polarizadas por projetos democraticamente deficitários, não raro apoiados em exercícios de repressão dos seus detratores. Uma possível saída para este problema passa por uma maior sustentação das políticas e das iniciativas, apoiadas num projeto global e partilhado que inclua a participação das populações no seu núcleo. Portanto, a afirmação da necessidade e importância do desenvolvimento como um processo inacabado e aberto a uma escolha democrática, que por isso é capaz de mobilizar vontades num sentido emancipador, é, como tentámos demonstrar, o modo de salvar a própria ideia de desenvolvimento.

\section{BIBLIOGRAFIA}

BENNETT, Robert J. (1993), “European Local Government Systems”, in R. J. Bennett (ed.), Local Government in the New Europe, Londres, Belhaven Press: 28-47.

BOURS, Adriaan (1993), “Management, tiers, size and amalgamations of local government”, in R. J. Bennett (ed.), Local Government in the New Europe, Londres, Belhaven Press: 109-129.

CABRITA, Eduardo (2008), "Comemorações do Feriado Municipal de Murça" - Intervenção do Secretário de Estado [online], disponível em: http://www.seaal.gov.pt/seaal/pt/int/20080508. htm [consultado em maio de 2008, texto agora indisponível].

CAMPEÃO DAS PROVÍNCIAS (2007), “Autarcas não gostam nada da participação”, Entrevista com Fernando Ruivo, conduzida por Paula A. Almeida, Edição de 1 de fevereiro de 2007 [online], disponível em: http://tinyurl.com/nttzwtw [consultado em março de 2012].

CARVALHO, João; FERNANDES, Maria José; CAMÕES, Pedro; JORGE, Susana (2005), Anuário Financeiro dos Municípios Portugueses - 2005, Lisboa, Câmara dos Técnicos Oficiais de Contas.

CUNHA, Jorge C. da e SILVA, Patrícia (2002), "Finanças locais e consolidação orçamental em Portugal”, in Banco de Portugal - Boletim Económico: 47-56. 
DIÁRIO DA REPÚBLICA (1990), “Resolução da Assembleia da República 28/90 de 23/10”, I Série: 4344-4351.

DGAEP (Direção-Geral da Administração e do Emprego Público) (2011), "Boletim do Observatório do Emprego Público -- Setembro de 2011”, Lisboa, DGAEP [online], disponível em: http:// tinyurl.com/prdvys3 [consultado em março de 2012].

DGAL (Direcção-Geral da Administração Local) (2010), “Balanço Social - Caracterização dos Recursos Humanos dos Municípios: 2009”, Lisboa, DGAL [online], disponível em: http:// tinyurl.com/o2zp2ru [consultado em março de 2012].

GOLDSMITH, Michael (1992), “Local Government”, Urban Studies, n.o 29 (3/4): 393-410.

LIDSTRÖM, Anders (1999), "The comparative study of local government: a research agenda", Journal of Comparative Policy Analysis, n. 1: 97-115.

MACEDO, Marta; PINTO, Marta; MACEDO, Pedro e SILVA, Margarida (2012), “Agenda 21 Local em Portugal - Balanço realizado com base na comunicação através da internet”, [online], disponível em: ttp://tinyurl.com/owvbd5c [consultado em março de 2012].

MACMAHON, Arthur W. (1961), Delegation and Autonomy, Bombay, Asia Publishing House.

NORTON, Alan (1994), International Handbook of Local and Regional Government. A Comparative Analysis of Advanced Democracies, Aldershot, Edward Elgar.

ONU (Organização das Nações Unidas) (1992), United Nations Conference on Environment \& Development - Agenda 21, Nova Iorque, United Nations Department of Economic and Social Affairs, Division for Sustainable Development [online], disponível em: http://tinyurl.com/ca6734h [consultado em março de 2012].

RODDEN, Jonathan (2005), "Federalismo e descentralização em perspectiva comparada: sobre significados e medidas", Revista de Sociologia e Política (Universidade Federal do Paraná), n.o 24: 9-27.

RTP (Rádio e Televisão de Portugal) (2012), “Orçamentos Participativos em Portugal: 10 anos em balanço" (Programa iGOV) [online], disponível em: http://tinyurl.com/oegruyg [consultado em janeiro de 2013].

SCHMIDT, Luísa e GUERRA, João (2010), "Da governança global à sustentabilidade local: Portugal e o Brasil em perspectiva comparada”, Revista de Ciências Sociais (Fortaleza), Vol. 41, 2: 106-124.

THYNNE, Ian e WETTENHALL, Roger (2004), "Public management and organizational autonomy: the continuing relevance of significant earlier knowledge", International Review of Administrative Sciences, Vol. 70 (4): 609-621.

\section{RESUMOS}

Propõe-se uma caracterização da arquitetura geral do poder local português, recorrendo, sobretudo, à análise de contributos de alguns autores que procuraram definir alguns critérios para uma tipificação comparativa de poderes locais e regionais de diversos países. A especificidade do caso português é analisada a partir de algumas das características que lhe são mais comummente reconhecidas: a sua natureza de poder algo marginalizado no contexto político português, decorrente em parte da sua vocação originária de contrapeso local de um sistema excessivamente burocrático e centralizador. A este propósito, referem-se os casos da situação verificada em termos de qualificação dos recursos humanos e da adoção da chamada Agenda 21 Local para o desenvolvimento sustentável. Enfim, argumenta-se que uma eventual 
mudança em favor de um maior envolvimento do poder local nas políticas de desenvolvimento do país será mais efetiva se as autarquias locais (especialmente os municípios mais pequenos e as freguesias) virem reforçados os seus recursos para poderem lançar novas iniciativas que possam estimular a participação dos cidadãos.

The text advances a characterization of the general architecture of Portuguese local government, resorting mainly to the analysis of contributions of some authors who attempted to set some criteria for a comparative classification of local and regional governments from different countries. The specificity of the Portuguese case is analyzed based on some of the features that are most commonly recognized: its nature of a level of government somewhat marginalized in the Portuguese political context, deriving in part from its original vocation of a local counterweight of a bureaucratic and centralized political system. In this regard the text refers the cases of the contrasting education levels of workers allocated to central and local administrations and of the adoption of the UN Local Agenda 21 for sustainable development. Finally, it is argued that any change in favor of a larger involvement of local governments in the development policies of the country will be more effective if especially the smaller municipalities see strengthened their resources in order to launch new initiatives which may encourage the citizen's participation.

Le document propose une caractérisation de l'architecture générale du pouvoir local portugais recourant principalement à l'analyse des contributions de auteurs qui ont tenté de fixer des critères pour une classification comparative des autorités locales et régionales de différents pays. La spécificité du cas portugais est analysé à partir de certaines des caractéristiques qui lui sont plus couramment reconnues: la nature d'un pouvoir quelque peu marginalisé au sein du système politique, résultant en partie de sa vocation à constituer un contrepoids d'un système bureaucratique et centralisateur. À cet égard, le texte se réfère à la situation en termes de niveau de scolarité des travailleurs affectés à l'administration centrale et locale et aussi à l'adoption de l'Agenda 21 Local pour le développement durable. Enfin, il est dit qu'un changement possible en faveur d'une plus grande implication du pouvoir local dans les politiques de développement du pays sera plus efficace si les autorités locales (en particulier les petites communes) peuvent voir renforcés leurs ressources afin de lancer de nouvelles initiatives pour encourager la participation des citoyens.

\section{ÍNDICE}

Palavras-chave: poder local, comparação internacional, desenvolvimento sustentável

Keywords: Local government, international comparison, sustainable development

Mots-clés: pouvoir local, comparaison internationale, développement durable

\section{AUTOR}

\section{JOEL FELIZES}

Sociólogo. Centro de Investigação em Ciências Sociais

jbfelizes@ics.uminho.pt 